\title{
VALUE RELEVANCE DOS OUTROS RESULTADOS ABRANGENTES NAS COMPANHIAS ABERTAS BRASILEIRAS ${ }^{1}$
}

\author{
Fabio Lopes Madeira ${ }^{2}$ \\ Jorge Vieira da Costa Junior ${ }^{3}$
}

Resumo: As normas internacionais de contabilidade inseriram no arcabouço contábil brasileiro, novos critérios de reconhecimento, mensuração e divulgação que divergiam dos existentes até então. Dentre essas novas práticas destacam-se os outros resultados abrangentes, que são ganhos e perdas não realizados reconhecidos diretamente no patrimônio líquido decorrentes de remensurações de determinadas rubricas do balanço patrimonial. Assim, o presente estudo teve por objetivo investigar o conteúdo informacional para o mercado de capitais dos outros resultados abrangentes das companhias integrantes do IBOVESPA nos exercícios de 2010 e 2011 . Utilizando o modelo de Ohlson (1995), foi evidenciado que os outros resultados abrangentes não possuem relação estatisticamente significativa com o valor de mercado das empresas no período analisado. As possíveis explicações desses resultados repousam na falta de entendimento do mercado dessa nova rubrica devido à sua recente inclusão nas demonstrações contábeis, na baixa qualidade de evidenciação dos outros resultados abrangentes pelas empresas, impactando o correto entendimento pelo mercado de capitais e o tamanho da amostra que foi afetada pela falta de valores dessa rubrica em $20 \%$ das companhias componentes do IBOVESPA.

Palavras-chave: Outros Resultados Abrangentes; Relevância Informacional; Normas Internacionais de Contabilidade.

\footnotetext{
Artigo apresentado no VIII Congresso Anpcont, no Rio de Janeiro, dias 17 a 20 de agosto de 2014.

2 E-mail: professor.fabiomadeira@gmail.com. Universidade do Estado do Rio de Janeiro - UERJ

${ }^{3}$ E-mail: jorgevcosta@terra.com.br. Universidade do Estado do Rio de Janeiro - UERJ

- DOI: http://dx.doi.org/10.14392/asaa.2015080204

- Artigo submetido em: 07/09/2014. Correções obrigatórias: 01/10/2014. Aceito em: 09/04/2015.
} 


\title{
VALUE RELEVANCE OF OTHER COMPREHENSIVE INCOME IN BRAZILIAN COMPANIES
}

\begin{abstract}
The international accounting standards inserted in the Brazilian accounting framework, new criteria for recognition, measurement and disclosure that differed from existing hitherto. Among these new practices stand out from other comprehensive income, that are unrealized gains and losses recognized directly in equity arising from remeasurements of certain items of the balance sheet. Thus, the present study aimed to investigate the informational content of other comprehensive income to the capital market of the member companies of the IBOVESPA for the years 2010 and 2011. Using the model of Ohlson (1995), it was evident that other comprehensive income not has statistically significant relationship with the market value of companies in the analyzed period. Possible explanations of these results lie in the lack of understanding of the market this new line due to its recent inclusion in the financial statements, the low quality of disclosure of other comprehensive income by the companies, impacting the correct understanding by capital market, and the sample size that was affected by the lack of values of that item by $20 \%$ of companies in the IBOVESPA.
\end{abstract}

Keywords: Other Comprehensive Income; Value Relevance; International Accounting Standards. 


\section{INTRODUÇÃO}

A crescente globalização da economia permitiu uma maior interação entre os diversos países ao redor do mundo, possibilitando para as empresas um aumento do mercado consumidor de seus produtos e o acesso a recursos de investidores estrangeiros. Um conjunto único de normas contábeis facilitaria a captação e a redução do custo desses recursos, pois o interesse dos investidores estrangeiros aumentaria na medida em que conhecessem, entendessem e confiassem nas informações contábeis disponíveis (ludícibus et al., 2010). Nesse sentido foram criadas as normas internacionais de contabilidade que atualmente são adotadas por diversos países ao redor do globo, dentre eles o Brasil.

A adoção desse novo conjunto de normas provocou enormes mudanças no ambiente contábil brasileiro, pois foram introduzidos novos critérios de reconhecimento, mensuração e divulgação que divergiam dos existentes até então. Dentre essas novas práticas contábeis, destaca-se o registro de itens diretamente no patrimônio líquido, conhecidos como outros resultados abrangentes, que incluem ganhos e perdas não realizados decorrentes de remensurações de determinadas rubricas do balanço patrimonial. Após a ocorrência de determinados eventos ou transações, alguns componentes dos outros resultados abrangentes são transferidos para o resultado do exercício.

A justificativa para essa prática contábil reside no entendimento de que as novas mensurações são muito voláteis, logo não acrescentariam utilidade ao lucro líquido (Jones \& Smith, 2011). Por essa razão, diversas pesquisas têm sido realizadas no intuito de investigar o conteúdo informacional dos outros resultados abrangentes para o mercado de capitais (Soo \& Soo, 1994; Dhaliwal, Subramanyam e Trezevant, 1999; Louis, 2003; Chambers et al., 2007; Kanagaretnam, Mathieu e Shehata, 2009; Jones \& Smith, 2011). Desse modo, o objetivo deste estudo é investigar o value relevance dos outros resultados abrangentes das companhias abertas brasileiras.

Esta pesquisa é justificada por contribuir com o entendimento da importância dispensada pelos investidores aos outros resultados abrangentes no que se refere à precificação das ações e também pela sua contribuição à literatura de value relevance das rubricas contábeis inseridas na adoção das normas internacionais de contabilidade. Na próxima seção é apresentada a fundamentação teórica. Na seção 3 são descritos os procedimentos metodológicos empregados. Na seção 4 são analisados os resultados obtidos e por fim na seção 5 são tecidas as considerações finais.

\section{REFERENCIAL TEÓRICO 2.1 Outros Resultados Abrangentes}

A origem dos outros resultados abrangentes nos remete a uma discussão existente desde as primeiras décadas do século XX, sobre qual seria a forma mais adequada de divulgar o resultado contábil: Se pelo conceito do resultado operacional corrente (current operating performance) ou através do conceito de resultado abrangente (all-inclusive) (Dhaliwal, Subramanyam e Trezevant, 1999; Rees \& Shane, 2012).

No modelo de resultado operacional corrente, somente são incluídas as receitas e despesas decorrentes das operações normais da empresa no período atual, assim os eventos e transações extraordinários e não recorrentes são excluídos da mensuração do resultado. Por outro lado, no modelo 
de resultado abrangente são reconhecidas no resultado todas as mutações ocorridas no patrimônio líquido que não sejam decorrentes das transações com os proprietários da empresa, como aumento de capital e distribuição de dividendos (Dhaliwal, Subramanyam e Trezevant, 1999; Hendriksen \& Van Breda, 1999; ludícibus, 2006).

Os defensores do conceito de resultado operacional corrente afirmam que esse modelo é mais útil aos investidores no sentido de auxiliar na predição de fluxos de caixa futuros da empresa, pois somente reporta itens recorrentes e relativos às atividades operacionais (Dhaliwal, Subramanyam e Trezevant, 1999; Hendriksen \& Van Breda, 1999; Chambers et al., 2007; Rees \& Shane, 2012).

Por sua vez, os adeptos ao conceito de resultado abrangente apresentam diversas vantagens desse modelo de mensuração do lucro. Em primeiro lugar, afirmam que o resultado abrangente mensura de forma mais adequada o desempenho da empresa, pois reporta todas as variações no patrimônio líquido da empresa no período, exceto aquelas referentes às transações com sócios e acionistas, desta forma reduzindo a discricionariedade dos administradores na inclusão de itens ou não na demonstração do resultado e assim diminuindo as chances de gerenciamento de resultados (Dhaliwal, Subramanyame e Trezevant, 1999; Hendriksen \& Van Breda, 1999; Chambers et al., 2007). Outra vantagem desse modelo é que ele está alinhado ao conceito de lucro limpo (clean surplus) onde todas as variações nos valores de ativos e passivos devem passar pela demonstração de resultado, resultando desta forma em uma integração entre a demonstração do resultado e o balanço patrimonial (Ohlson, 1995; Chambers at al., 2007; Coelho \& Carvalho, 2007; Pinheiro, Macedo e Vilamaior, 2012).

Entretanto, os contrários ao resultado abrangente apontam problemas como: i) aumento da volatilidade do resultado, promovendo incremento da percepção de risco associado à empresa e ii) a inclusão de itens transitórios que não refletem o resultado da atividade (core business), prejudicando assim a análise de desempenho dos gestores e previsão de resultados futuros (Lee, Petroni e Shen, 2006; Chambers et al., 2007).

Em meio a argumentos contrários e favoráveis à apresentação do resultado abrangente, o Financial Accounting Standards Board (FASB), órgão regulador americano, emitiu em 1997 o SFAS n. 130 (Reporting comprehensive income) que passou a exigir a divulgação do resultado abrangente nas demonstrações contábeis da empresa. A norma fornecia às empresas três alternativas para reportar o resultado abrangente: i) em uma única demonstração de resultados, onde o resultado abrangente total seria reportado após o lucro líquido; ii) em uma demonstração do resultado abrangente separada, onde seria iniciada com o lucro líquido ou iii) na demonstração das mutações do patrimônio líquido. Apesar das opções facultadas pelo normativo, o FASB encorajava as companhias a relatar o resultado abrangente através da demonstração do resultado (Chambers et al., 2007).

A inovação provocada pelo SFAS 130 residia na divulgação dos outros resultados abrangentes (other comprehensive income) no corpo das demonstrações contábeis. Assim, ocorreu uma junção entre o lucro líquido, que era historicamente divulgado, e os outros resultados abrangentes, que não apareciam destacadamente nos relatórios financeiros, para desta união surgir o resultado abrangente total.

Essa norma definiu os outros resultados abrangentes por exclusão, isto é, aqueles classificados como receitas, despesas, ganhos e perdas que são reconhecidos no resultado abrangente, porém não o são no 
lucro líquido do período (Fasb, 1997). De uma forma mais específica, os outros resultados abrangentes, sob as normas contábeis norte-americanas, são ganhos e perdas ainda não realizados reconhecidos diretamente em conta separada do patrimônio líquido decorrentes de ajustes de conversão cambial; ajustes a valor de mercado de títulos classificados como disponíveis para venda e de derivativos que se classificam como hedge de fluxo de caixa ou de moeda estrangeira e ajustes da obrigação mínima de fundos de pensão. Por fim, o SFAS 130 obriga que todos os itens de outros resultados abrangentes sejam em algum momento "reciclados para o resultado". Por exemplo, os ganhos ou perdas não realizados de instrumentos financeiros classificados como disponíveis para venda que foram reconhecidos anteriormente em outros resultados abrangentes, no momento da alienação desses títulos os valores desses ganhos ou perdas devem ser reconhecidos no lucro líquido, entretanto para evitar a dupla contagem no resultado abrangente total, deve-se realizar um ajuste de reclassificação desses valores na rubrica de outros resultados abrangentes (Fasb, 1997).

No Brasil, antes das mudanças iniciadas pela Lei n. ${ }^{\circ} 11.638 / 07$, a demonstração do resultado poderia ser considerada "hibrida", pois possuía características do conceito do resultado operacional corrente como os ajustes de exercícios anteriores, as reservas de capital e a reavaliação de ativos que eram registradas diretamente no patrimônio líquido e de características do modelo de resultado abrangente como o registro no resultado dos ajustes normais decorrentes de erros de estimativas contábeis (ludícibus \& Martins, 2007). Entretanto, apesar de conter algumas características do conceito de resultado abrangente, as empresas divulgavam apenas o lucro líquido do exercício e os valores reconhecidos no patrimônio líquido nunca eram reclassificados para o resultado. Somente após a publicação da Lei $n .{ }^{\circ}$ 11.638/07 que iniciou o processo brasileiro de convergência às normas internacionais de contabilidade (IFRS), que o ambiente contábil brasileiro passou a contar com as figuras da demonstração do resultado abrangente e, por consequência, com os outros resultados abrangentes.

A norma internacional IAS 1 (apresentação das demonstrações contábeis) em sua revisão de setembro de 2007 foi influenciada pela SFAS 130 no sentido de também exigir que a empresa divulgue o resultado abrangente do período, contudo a norma internacional forneceu apenas duas opções de apresentação dos outros resultados abrangentes: em uma única demonstração de resultado ou em uma demonstração do resultado abrangente separada (Rees \& Shane, 2012; Mackenzie et al., 2013). No Brasil, na primeira versão do Pronunciamento Técnico n. ${ }^{2} 6$ (CPC 26), que correspondia a tradução da IAS 1, existia a permissão da apresentação da demonstração do resultado abrangente como parte da demonstração das mutações do patrimônio líquido. Entretanto, a partir do ano de 2011, com a revisão da norma brasileira, essa permissão foi retirada, assim as empresas brasileiras passaram a ser obrigadas a apresentar separadamente a demonstração do resultado abrangente do período.

O CPC 26 define os outros resultados abrangentes como "itens de receita e despesa (incluindo ajustes de reclassificação) que não são reconhecidos na demonstração do resultado como requerido ou permitido pelos Pronunciamentos, Interpretações e Orientações emitidos pelo CPC" (CPC, 2011a). Este mesmo pronunciamento lista os itens de compõe os outros resultados abrangentes:

a) variações na reserva de reavaliação dos itens do ativo imobilizado e intangível (CPC 27 e 04);

b) ganhos e perdas atuarias em planos de pensão de benefício definido (CPC 33);

c) ganhos e perdas decorrentes da conversão de demonstrações contábeis de empresas no exterior (CPC 02);

d) ganhos e perdas na mensuração a valor justo de instrumentos financeiros classificados como disponíveis para venda (CPC 38);

e) ganhos e perdas referente a parcela efetiva de hedge de fluxo de caixa (CPC 38). 
Ao contrário do SFAS 130, nas normas internacionais nem todos os itens de outros resultados abrangentes são posteriormente reclassificados para o lucro líquido. Na baixa de investimentos em empresas no exterior, de instrumentos financeiros disponíveis para venda e quando a transação sujeita a hedge de fluxo de caixa impacta o resultado, os ganhos e perdas anteriormente reconhecidos como outros resultados abrangentes são reclassificados para o resultado do período (CPC, 2011a). Entretanto, os valores referentes à reavaliação de ativos imobilizados e/ou intangíveis e os ganhos ou perdas atuarias de planos de pensão nunca são reclassificados para o resultado do período. O quadro 1 resume o tratamento dos outros resultados abrangentes segundo as normas IFRS:

Quadro 1 - Tratamento dos outros resultados abrangentes nas IFRS

\begin{tabular}{|c|c|c|}
\hline Item & Norma & Reclassificação para o resultado \\
\hline Reavaliação de ativos imobilizados e intangíveis & CPC 27 e 04 & $\begin{array}{l}\text { Não. O montante da reserva de reavaliação pode ser } \\
\text { transferido para a conta de lucros acumulados à medida } \\
\text { que o ativo reavaliado é utilizado ou baixado. }\end{array}$ \\
\hline Ganhos e perdas atuariais em planos de pensão & CPC 33 & Não. \\
\hline $\begin{array}{l}\text { Variação cambial decorrentes de conversão de de- } \\
\text { monstrações contábeis de investimentos no exterior }\end{array}$ & CPC 02 & Sim, no momento da baixa do investimento no exterior \\
\hline $\begin{array}{c}\text { Ganhos e perdas referentes à mensuração a valor } \\
\text { justo de instrumentos financeiros classificados como } \\
\text { disponíveis para venda }\end{array}$ & CPC 38 & $\begin{array}{l}\text { Sim, no momento do desreconhecimento do instrumento } \\
\text { financeiro (ex. na alienação ou baixa). }\end{array}$ \\
\hline $\begin{array}{c}\text { Ganhos e perdas referentes à parcela efetiva de } \mathrm{He}- \\
\text { dge de fluxo de caixa }\end{array}$ & CPC 38 & Sim, quando a transação sujeita a hedge afeta o resultado. \\
\hline
\end{tabular}

Fonte: Dados da pesquisa (2014).

De forma semelhante ao SFAS 130, o CPC 26 dispõe que para os itens que são "reciclados", no período em que o ganho ou perda é reconhecido no resultado, o montante do ganho ou perda também deve ser apresentado como ajuste de reclassificação na demonstração do resultado abrangente, de maneira que esse ganho ou perda não seja registrado em duplicidade.

\subsection{Value Relevance dos Outros Resultados Abrangentes}

A Contabilidade tem por objetivo principal o fornecimento de informações úteis que subsidiem a tomada de decisões econômicas por parte de seus diversos usuários. Para ser útil a informação contábil deve ser relevante, isto é, deve representar um diferencial para o usuário na decisão a ser tomada (Cpc, 2011b). Nesse sentido, os estudos sobre value relevance tem por finalidade desenvolver o entendimento sobre a relevância e a confiabilidade dos números contábeis através de sua correlação com os valores de mercado (Barth, Beaver e Landsman, 2001).

As pesquisas sobre o relacionamento entre os números contábeis e os preços das ações tiveram inicio com o trabalho seminal de Ball e Brown (1968) que provaram empiricamente a relação entre lucro contábil e o preço dos títulos negociados. Contudo Barth, Beaver e Landsman (2001) comentam que a primeira pesquisa a utilizar a nomenclatura de value relevance para descrever essa relação entre números contábeis e valores de mercado foi o de Amir et al. (1993). 
Por sua vez, Holthausen e Watts (2001) propuseram a classificação dos estudos sobre value relevance em três categorias:

a) Estudos de associação relativa: investigam a associação entre os preços (ou retornos) de mercado e números contábeis mensurados com diferentes normas contábeis. A norma que gera um número contábil mais value relevant é a que possui a regressão com o maior $\mathrm{R}^{2}$;

b) Estudos de associação incremental: analisam se o numero contábil explica o valor ou retorno de títulos em períodos mais longos de tempo considerando outras variáveis. Se o coeficiente da regressão for diferente de zero, o número contábil é considerado value relevant;

c) Estudos de conteúdo informacional marginal: avaliam se um dado número contábil agrega conteúdo às informações divulgadas ao mercado. Geralmente fazem uso de estudos de eventos para verificar se a divulgação de um número contábil está atrelada a alterações de valor no preço dos títulos, isto é, se ocorrer reações nos preços, a informação é considerada value relevant.

Com relação aos outros resultados abrangentes, os estudos realizados até o momento evidenciam que a maior parte dos itens que compõe esse grupo são value relevant. Contudo os achados dessas pesquisas também mostram diferenças significativas de value relevance entre estes itens (Rees \& Shane, 2012).

Soo e Soo (1994) investigaram se os ganhos e perdas decorrentes de ajustes de conversão de demonstrações contábeis introduzidos pelo SFAS 52 eram incorporados pelo mercado de capitais. Os resultados apontaram que o mercado utiliza os valores dos ajustes de conversão reconhecidos no patrimônio líquido na precificação dos títulos. Entretanto os autores ressaltam que o efeito desse item nos preços das ações é menor do que de outros componentes do resultado.

Já Dhaliwal, Subramanyan e Trezevant (1999) buscando, entre outros objetivos, analisar o value relevance dos itens que compõem os outros resultados abrangentes segundo o SFAS 130 (ganhos e perdas não realizados de títulos disponíveis para venda, ajustes acumulados de conversão de demonstrações contábeis e ajustes da obrigação mínima de fundos de pensão), encontraram evidência de value relevance apenas para os ajustes dos títulos disponíveis para venda das empresas do setor financeiro.

Louis (2003), analisando uma amostra de indústrias multinacionais no período de 1985 a 2001, evidenciou que o ajuste de conversão de demonstrações contábeis é value relevant, mas não na direção do ajuste, isto é, um ajuste positivo no patrimônio representa uma perda de valor de mercado. Segundo o autor, esse resultado se justifica, pois um ajuste positivo representa uma valorização da moeda de origem da subsidiária, assim, em um mercado competitivo, os produtos estrangeiros ficam mais baratos, forçando a subsidiária a reduzir seus preços e consequentemente reduzindo seus lucros e seu valor de mercado.

Por sua vez, Chambers et al. (2007) através de uma análise manual do relatório 10K das companhias norte americanas listadas no índice S\&P 500 investigaram se os outros resultados abrangentes divulgados eram precificados pelo mercado. Os resultados comprovaram que os outros resultados abrangentes eram precificados pelos investidores. Os autores verificaram também a precificação individual dos itens dos outros resultados abrangentes, encontrando confirmação para os ganhos e perdas não realizados de títulos disponíveis para venda e dos ajustes acumulados de conversão.

Kanagaretnam, Mathieu e Shehata (2009) analisaram o value relevance do resultado abrangente e dos componentes dos outros resultados abrangentes em amostra de companhias canadenses componentes do índice TSE 300 de Bolsa de Valores de Toronto e que também estivessem listadas na NYSE, ASE ou na NASDAQ no período de 1998 a 2003. Os autores encontraram associação entre dois componentes dos outros resultados abrangentes (ganhos e perdas de títulos disponíveis para venda e hedge de fluxo 
de caixa) e valores (preço e retorno) de mercado. Por fim, foi evidenciado que o resultado abrangente está mais associado com preço e retorno de mercado quando comparado com o lucro líquido.

E por fim, Jones e Smith (2011) compararam o value relevance, valor preditivo e a persistência dos outros resultados abrangentes e dos itens especiais de 236 companhias no período compreendido entre 1986 e 2005. Os autores documentaram que tanto os outros resultados abrangentes quantos os itens especiais são value relevant, porém em menor intensidade grau para os primeiros. Em relação à persistência, os itens especiais não apresentaram persistência, enquanto os outros resultados abrangentes apresentaram persistência negativa (possivelmente referente a reversão ao longo do tempo). E no que diz respeito ao valor preditivo, os itens especiais são consistentemente associados positivamente com lucros e fluxos de caixas futuros, ao contrário dos outros resultados abrangentes que tiveram a capacidade de predição em todos os períodos, e com uma relação de menor grau do que os itens especiais.

3 METODOLOGIA 3.1 Seleção da Amostra

A amostra da pesquisa compreendeu as 66 companhias brasileiras integrantes do IBOVESPA em 04/11/2013. A justificativa para a escolha dessa amostra reside no fato de que as empresas componentes desse índice respondem por mais de $80 \%$ do número de negócios e do volume financeiro ocorridos na Bolsa de Valores de São Paulo (BM\&FBOVESPA, 2014).

Inicialmente foram retiradas da amostra as instituições financeiras (5), holdings (2) e companhias com atividade de serviços financeiros diversos (3). Tal procedimento é justificado pelas características específicas desses segmentos econômicos. A seguir foram excluídas duas companhias que eram controladas por outra empresa integrante do índice, pois suas informações estão consolidadas na empresa controladora. Também foi retirada uma companhia que não possuía exercício social encerrado em 31 de dezembro. Por fim foram eliminadas as empresas que não possuíam valores de outros resultados abrangentes (ORA) em pelo menos um dos períodos analisados. A amostra final foi composta por 40 empresas conforme demonstrado na tabela 1:

Tabela 1 - Composição da amostra

\begin{tabular}{|c|c|}
\hline Total das empresas componentes do IBOVESPA & 66 \\
\hline$(-)$ Instituições Financeiras & $(5)$ \\
\hline$(-)$ Holdings & $(2)$ \\
\hline (-) Companhias de serviços financeiros & $(3)$ \\
\hline (-) Companhias com controladoras no índice & $(2)$ \\
\hline (-) Companhias com encerramento do exercício social diferente de 31/12 & $(1)$ \\
\hline (-) Companhias que não possuíam valores de ORA nos períodos analisados & $(13)$ \\
\hline (=) Amostra final & 40 \\
\hline
\end{tabular}

Fonte: Dados da pesquisa (2014).

O período analisado compreendeu os exercícios sociais de 2010 e 2011. A escolha desse período foi motivada pelo fato de 2010 constituir o primeiro exercício social em que as companhias abertas foram obrigadas a divulgar suas informações contábeis em full IFRS. 


\subsection{Desenvolvimento da Hipótese e Teste Estatístico}

Apesar dos argumentos de que os outros resultados abrangentes são compostos de itens não recorrentes e transitórios e que por isso não seriam capazes de explicar retorno ou preços de ações (Rees \& Shane, 2012), estudos anteriores evidenciaram o contrário, isto é, que os outros resultados abrangentes estão relacionados com os preços de mercado. Assim, formulou-se a seguinte hipótese:

Hipótese 1: Os outros resultados abrangentes possuem value relevance para o mercado de capitais brasileiro.

Para testar estar hipótese foi utilizado o modelo de Ohlson (1995) que consiste em um modelo linear no qual o valor de mercado da empresa é igual ao seu patrimônio líquido mais os lucros anormais e o termo de erro que representa as demais informações que impactam o valor da empresa (Lopes, 2002). Assim o modelo utilizado nesta pesquisa foi:

$V M E_{i t}=a_{0}+\beta_{1} P L *_{i t}+\beta_{2} O R A_{i t}+\beta_{3} A b n E a r_{i t}+\varepsilon_{i t}$

Onde:

(a) $\mathrm{VME}_{\text {it }}$ : valor de mercado da empresa i no ano t na data $\mathrm{d}+5$, onde $\mathrm{d}$ refere-se à data da primeira entrega das Demonstrações Financeiras Padronizadas (DFP) disponível no site da Comissão de Valores Mobiliários;

(b) $\mathrm{PL}_{\text {wit }_{\mathrm{it}}}$ : valor do patrimônio líquido da empresa i no ano t sem o valor dos outros resultados abrangentes;

(c) $\mathrm{ORA}_{\mathrm{it}}$ : valor dos outros resultados abrangentes da empresa i no ano t;

(d) AbnEar ${ }_{i t}$ : valor do lucro anormal da empresa i no ano t.

Todas as variáveis da equação foram escalonadas pelo valor contábil do ativo total. Os valores de mercado das empresas, patrimônio líquido e ativo total foram obtidos na base de dados Economatica, enquanto o valor dos outros resultados abrangentes foi coletado manualmente nas demonstrações contábeis das empresas. Para o cálculo do lucro anormal das companhias foi utilizada a proxy proposta por Ohlson (1995) através da seguinte fórmula:

$$
\text { AbnEar }_{i t}=L L_{\mathrm{it}}-P L_{\mathrm{it}-1} * R
$$

$\mathrm{Na}$ equação 2, $\mathrm{LL}_{\mathrm{it}}$ representa o lucro líquido da empresa i no ano t e $\mathrm{PL}_{\mathrm{it}-1}{ }^{*} \mathrm{R}$ refere-se ao valor do patrimônio líquido da empresa i no ano t-1 multiplicado pela taxa livre de risco do período. Nessa pesquisa foi utilizada a SELIC como taxa livre de risco. As variáveis da parte direita da equação foram coletadas no software Economatica.

\section{ANÁLISE DOS RESULTADOS}

Na tabela 2 são apresentadas as estatísticas descritivas das variáveis pertencentes a amostra referentes aos anos de 2010 e 2011 : 
Tabela 1 - Composição da amostra

\begin{tabular}{|c|c|c|c|c|c|}
\hline \multicolumn{7}{|c|}{ Painel 1 - Estatística descritiva - 2010 } \\
\hline & N & Mínimo & Máximo & Média & Desvio Padrão \\
\hline VME & 40 & 3.774 .560 & 408.988 .516 & 31.833 .209 & 76.288 .992 \\
\hline PL & 40 & 452.672 & 306.765 .182 & 18.285 .495 & 50.883 .889 \\
\hline PL* & 40 & 450.271 & 306.674 .577 & 18.281 .696 & 51.401 .194 \\
\hline ORA & 40 & -9.537 .609 & 3.449 .939 & 3.799 & 1.848 .561 \\
\hline AbnEar & 40 & -3.761 .854 & 25.861 .944 & 694.960 & 4.372 .319 \\
\hline & & Painel 2- Estatística descritiva - 2011 & \\
\hline & N & Mínimo & Máximo & Média & Desvio Padrão \\
\hline VME & 40 & 2.860 .378 & 315.266 .098 & 30.882 .925 & 65.146 .503 \\
\hline PL & 40 & 690.490 & 329.838 .881 & 20.919 .373 & 56.048 .004 \\
\hline PL* & 40 & 687.591 & 328.566 .496 & 20.746 .686 & 55.978 .144 \\
\hline ORA & 40 & -2.648 .406 & 2.621 .339 & 172.688 & 988.715 \\
\hline AbnEar & 40 & -15.254 .857 & 7.716 .432 & -1.063 .195 & 3.752 .487 \\
\hline
\end{tabular}

Fonte: Dados da pesquisa (2014)

A maior parte do montante de outros resultados abrangentes das companhias componentes da amostra refere-se ganhos e perdas relativos à mensuração a valor justo de títulos e valores mobiliários classificados como disponíveis para venda e ajustes de variação cambial decorrentes de conversão de demonstrações contábeis de investimentos no exterior.

Em 2010, o valor médio dos outros resultados abrangentes atingiu $\mathrm{R} \$ 4$ milhões, enquanto que no exercício de 2011 esse valor saltou para R\$ 1 z73 milhões representando um crescimento de 4.225\% de um período para o outro. No ano de 2010 o valor médio dos outros resultados abrangentes representava 0,02\% da média do patrimônio líquido das empresas da amostra. Já no ano de 2011 a participação dessa rubrica no patrimônio líquido cresceu para 0,83\%.

Para constatar se os outros resultados abrangentes possuem value relevance para o mercado de capitais brasileiro foi utilizado o modelo de Ohlson para os anos de 2010 e 2011. A tabela 3 apresenta os resultados da equação 1:

Tabela 3 - Resultado das regressões referente à equação 1

\begin{tabular}{|c|c|c|}
\hline Descrição & 2010 & 2011 \\
\hline Intercepto & 0,416 & 0,446 \\
& $(0,350)$ & $(0,348)$ \\
\hline PL $^{*}$ & 1,543 & $2,226^{* *}$ \\
& $(0,917)$ & $(0,875)$ \\
\hline ORA & $-0,670$ & $-0,597$ \\
& $(1,947)$ & $(2,374)$ \\
\hline AbnEar & $11,466^{*}$ & $15,772^{*}$ \\
& $(2,041)$ & $(2,691)$ \\
\hline N & 40 & 40 \\
\hline$R^{2}$ & 0,660 & 0,782 \\
\hline Teste F & 11,62 & 20,55 \\
& $(0,000)$ & $(0,000)$ \\
\hline
\end{tabular}


Primeiramente destaca-se que os erros-padrão foram estimados com a correção de White, que segundo Fávero et al (2009, p. 390) este procedimento faz"com que eventuais problemas de heterocedasticidade sejam corrigidos e [...]" fornece "[...] estimadores mais consistentes e não viesados".

A adequação do modelo utilizado é comprovada pelo teste $F$, o qual apresentou significância estatística nos dois anos analisados. No ano de 2010, os outros resultados abrangentes não apresentaram significância estatística. Nesse exercício a única variável que apresentou significância foi o lucro anormal ao nível de 1\%. Do mesmo modo, no ano de 2011 a variável ORA mostrou-se insignificante estatisticamente, entretanto nesse período além da variável lucro anormal, o patrimônio líquido ajustado apresentou significância ao nível de 5\%.

Assim, não é possível confirmar a hipótese desse estudo, pois os outros resultados abrangentes não possuem relação estatisticamente significante com o valor de mercado das empresas componentes da amostra, isto é, não é value relevant para o mercado de capitais brasileiro, ao contrário dos resultados obtidos nos estudos anteriores realizados nos Estados Unidos e Canadá.

Entre os motivos que podem explicar estes resultados incluem-se: (i) a recente introdução dos outros resultados abrangentes no arcabouço contábil brasileiro, uma vez que a obrigatoriedade da elaboração e divulgação das demonstrações contábeis em IFRS começou no exercício de 2010. Assim o mercado de capitais pode não ter entendido e absorvido o conteúdo dessas informações de forma a impactar o preço das ações no período analisado, (ii) a baixa qualidade de evidenciação dessa rubrica nas demonstrações contábeis das empresas da amostra, que foi constatada na coleta de dados dessa pesquisa. Essa deficiência na divulgação pode ter comprometido a análise por parte dos investidores dos reais efeitos dos outros resultados abrangentes na composição patrimonial e desempenho das empresas e (iii) o tamanho reduzido da amostra, pois aproximadamente $20 \%$ das companhias do IBOVESPA não possuíam valores de outros resultados abrangentes reconhecidos em suas demonstrações contábeis no período de 2010 e 2011.

\section{CONSIDERAÇÕES FINAIS}

Este artigo teve por objetivo analisar a relevância informacional dos outros resultados abrangentes das companhias abertas brasileiras componentes do IBOVESPA nos exercícios de 2010 e 2011 . Os outros resultados abrangentes são compostos de ganhos e perdas não realizados registrados diretamente no patrimônio líquido. Essa rubrica foi inserida no Brasil durante o processo de convergência às normas contábeis internacionais, pois até então somente o reconhecimento da reserva de reavaliação, dos ajustes de exercícios anteriores e das reservas de capital tinham tratamento similar ao dos outros resultados abrangentes.

Através da utilização do modelo de Ohlson (1995) foi possível rejeitar a hipótese de pesquisa, isto é, os outros resultados abrangentes não possuem value relevance para o mercado de capitais brasileiro. No ano de 2010, apenas o lucro anormal apresentou relacionamento estatisticamente significante com o valor de mercado da empresa e em 2011, as variáveis patrimônio líquido e lucro anormal foram significativas ao nível de $5 \%$ e $1 \%$ respectivamente.

Possíveis explicações para os resultados obtidos residem no pouco tempo de vigência das práticas que regulam esta rubrica (a partir dos exercícios encerrados em 2010), assim os investidores ainda não teriam considerado adequadamente seus efeitos na precificação das ações nos anos analisados por esta pesquisa. Soma-se a isto o fato da fraca divulgação dos outros resultados abrangentes nas 
demonstrações financeiras das empresas, que possivelmente dificultou o correto entendimento pelos usuários dessas demonstrações dos impactos na situação econômico-financeira das empresas. E por fim, acrescenta-se ao rol de explicações, a inexistência de valores de outros resultados abrangentes em muitas companhias (aproximadamente 20\%) integrantes do IBOVESPA nos períodos analisados, o que impactou negativamente o tamanho da amostra e consequentemente a robustez dos resultados.

Com este trabalho abrem-se possibilidades de pesquisas futuras, uma vez que existem poucas pesquisas tratando deste tema. Sugere-se para futuras pesquisas o aumento da amostra, isto é, abrangendo todas as companhias abertas brasileiras para analisar se os outros resultados abrangentes são value relevant no mercado acionário brasileiro e também a investigação em exercícios posteriores a 2011, uma vez que, com o passar do tempo, as informações dos outros resultados abrangentes sejam mais inteligíveis aos investidores, podendo assim influenciar o valor de mercado das companhias.

\section{REFERÊNCIAS}

Ball, Ray \& Brown, Philip. (1968). An empirical evaluation of accounting income numbers. Journal of Accounting Research, 6, 159-178, autumn.

Barth, Mary E., Beaver, William H. e Landsman, Wayne R. (2001). The relevance of the value relevance literature for financial accounting standard setting: another view. Journal of Accounting \& Economics, 31, 77-104.

BM\&FBOVESPA. (2014). São Paulo, Brasil. Disponível em: http://www.bmfbovespa.com.br/indices/ Resumolndice.aspx?Indice=Ibovespa\&ldioma=pt-br. Acesso em: 5 jan. 2014.

Chambers, Dennis, Linsmeier, Thomas J., Shakespeare, Catherine e Sougiannis, Theodore. (2007). An evaluation of SFAS No. 130 comprehensive income disclosures. Review of Accounting Studies, 12, 557-593.

Coelho, Antônio Carlos \& Carvalho, Luiz Nelson. (maio/ago., 2007). Análise conceitual de lucro abrangente e lucro operacional corrente: evidências no setor financeiro brasileiro. Brazilian Business Review, 4(2), 119-139.

Comitê de Pronunciamento Contábeis. (2009). Pronunciamento Técnico CPC 27 - Ativo imobilizado. Brasília: junho.

Disponível em: <http://www.cpc.org.br/pdf/CPC_27_rev\%2003.doc>. Acesso em: 26 dez. 2013.

. (outubro, 2009). Pronunciamento Técnico CPC 38 - Instrumentos financeiros: reconhecimento e mensuração. Brasília, Brasil. Disponível em: <http://www.cpc.org.br/pdf/CPC_38_rev\%2003.doc>. Acesso em: 26 dez. 2013.

(setembro, 2010). Pronunciamento Técnico CPC 02 (R2) - Efeitos das mudanças nas taxas de câmbio e conversão de demonstrações contábeis. Brasília, Brasil. Disponível em: <http://www.cpc.org. br/pdf/CPC_02_R2_rev\%2003.doc>. Acesso em: 26 dez. 2013. 
(novembro, 2010). Pronunciamento Técnico CPC 04 (R1) - Ativo intangível. Brasília, Brasil. Disponível em: <http://www.cpc.org.br/pdf/CPC_04_R1_rev\%2003.doc>. Acesso em: 26 dez. 2013.

(dezembro, 2011a). Pronunciamento Técnico CPC 26 (R1) - Apresentação das Demonstrações Contábeis. Brasília, Brasil.

Disponível em: <http://www.cpc.org.br/pdf/CPC_26_R1_rev\%2003.doc>. Acesso em: 26 dez. 2013.

(dezembro, 2011b). Pronunciamento Conceitual Básico (R1) - Estrutura conceitual para elaboração e divulgação de relatório contábil-financeiro. Brasília, Brasil. Disponível em: <http://www.cpc.org. br/pdf/CPC00_R1_final.doc>. Acesso em: 26 dez. 2013.

(dezembro, 2012). Pronunciamento Técnico CPC 33 (R1) - Benefícios a empregados. Brasília, Brasil.

Disponível em: <http://www.cpc.org.br/pdf/CPC_33_R1_final.pdf>. Acesso em: 26 dez. 2013.

Dhaliwal, Dan, Subramanyam, K. R. e Trezevant, Robert. (1999). Is comprehensive income superior to net income as a mensure of firm performance? Jornal of Accounting and Economics, 26, 43-67.

Fávero, Luiz Paulo, Belfiore, Patrícia, Silva, Fabiana Lopes da e Chan, Betty Lilian. (2009). Análise de Dados: modelagem multivariada para tomada de decisões. Rio de Janeiro: Elsevier.

Financial Accounting Standards Board. (june, 1997). SFAS 130 - Reporting Comprehensive Income. Norwalk.

Hendriksen, Eldon S. \& Van Breda, Michael F. (1999). Teoria da Contabilidade. Tradução: Antônio Zoratto Sanvicente. São Paulo: Atlas.

Holthausen, Robert W. \&Watts, Ross L. (2001). The relevance of the value-relevance literature for financial accounting standard setting. Journal of Accounting \& Economics, 31, 3-75.

ludícibus, Sérgio de. (2006). Teoria da Contabilidade. 8. ed. São Paulo: Atlas, 2006.

Martins, Eliseu. (junho, 2007). Uma investigação e uma proposição sobre o conceito e o uso do valor justo. Revista Contabilidade \& Finanças, edição 30 anos de doutorado, 9-18.

Gelbcke, Ernesto Rubens e Santos, Ariovaldo dos. (2010). Manual de Contabilidade Societária. São Paulo: Atlas.

Jones, Denise A. \& Smith, Kimberly. (2011). Comparing the value relevance, predictive value, and persistence of other comprehensive income and special items. The Accounting Review, 86(6), 2047-2073.

Kanagaretnam, Kiridaran, Mathieu, Robert e Shehata, Mohamed. (jul./ago., 2009). Usefulness of comprehensive income reporting in Canada. Journal of Accounting and Public Policy, 28(4), 349-365. 
Lee, Yen-Jung, Petroni, Kathy R. e Shen, Min. (2006). Cherry Picking, disclosure quality, and comprehensive income reporting choices: the case of property-liability insurers. Contemporary Accounting Research, 23(3), 655-692, Fall.

Lopes, Alexsandro Broedel. (2002). A Informação Contábil e o Mercado de Capitais. São Paulo: Pioneira Thomson Learning.

Louis, Henock. (2003). The value relevance of the foreign translation adjustment. The Accounting Review, 78(4), 1027-1047.

Mackenzie, Bruce, Coetsee, Danie, Njikizana, Tapiwa, Chamboko, Raymond, Colyvas, Blaise e Hanekom. (2013). IFRS 2012: interpretação e aplicação. Tradução: Francisco Araújo da costa et al. Porto Alegre: Bookman.

Ohlson, James A. (1995). Earnings, book values, and dividends in equity valuation. Contemporary Accounting Research, 11(2), 661-687, spring.

Pinheiro, Laura Edith Taboada, Macedo, Rodney Pereira de e Vilamaior, Adriana Giarola. (out./dez., 2012). Lucro líquido versus lucro abrangente: uma análise empírica da volatilidade. Revista Universo Contábil, 8(4), 6-18.

Ress, Lynn L. \& Shane, Philip B. (2012). Academic research and standard-setting: the case of other comprehensive income. Accounting Horizons, 26(4), 789-815.

Soo, Billy \& Soo, Lisa Gilbert. (oct, 1994). Accounting for the multinational firm: is the translation process valued by stock market? The Accounting Review, 69(4), 617-637. 